Arab World English Journal (AWEJ) Volume 12. Number1 March 2021

DOI: https://dx.doi.org/10.24093/awej/vol12no1.31

Pp.480-497

\title{
The Effects of Situational and Perceived Interest on EFL Reading Comprehension: A Gender-Based Study at the University of Algiers 2
}

\author{
Mohammed Akhrib \\ English Department, Faculty of Foreign Languages \\ University of Algiers 2, Algiers, Algeria \\ Correspondent Author: akhribmoh@gmail.com
}

Fatma Zohra Mebtouche Nedjai

High School of Fine Arts, Algiers, Algeria

Received : 11/11/2020

Accepted: 3/13/2021

Published :3/24/2021

\begin{abstract}
This study aims to investigate gender differences in English as a foreign language (EFL) reading comprehension, situational and perceived interest for gender-oriented passages. It also examines whether any gender variances in situational or perceived interest in those passages cause gender differences in EFL reading comprehension. Throughout this research, clear insights about individual differences and the unexplained variance in foreign language reading are provided. Two main research questions were formulated: (a) Do gender differences in EFL students' situational interest explain gender differences in EFL students' reading comprehension? (b) Do gender differences in EFL students' PI explain gender differences in EFL students' reading comprehension? In this concern, EFL freshmen students at the University of Algiers 2, including 35 females and 24 males, were conveniently selected. The selected materials were two tests of reading comprehension with male and female texts. Each of these tests was followed by the questionnaires of sources of interest and perceived interest, adapted from Brantmeier (2006). Findings revealed significant gender differences in tests with male and female passages. Besides, significant gender differences found in cohesion, prior knowledge, ease of recollection, and perceived interest for both male and female passages in addition to engagement for the female text did not account for gender differences in reading comprehension of their respective tests. In this way, other factors than situational and perceived interest would explain gender differences in reading comprehension.

Keywords: English as a Foreign Language, gender based study at the University of Algiers 2, gender-oriented passages, perceived interest, reading comprehension, situational interess
\end{abstract}

Cite as: Akhrib, M. , \& Nedjai, F. Z. M. (2021). The Effects of Situational and Perceived Interest on EFL Reading Comprehension: A Gender-Based Study at the University of Algiers 2. Arab World English Journal, 12 (1) 480-497. DOI:https://dx.doi.org/10.24093/awej/vol12no1.31 


\section{Introduction}

Reading evokes mental representations drawn out of textual features and discourse in print (Kintsch, 2013). This assumption had raised debates over the nature of EFL reading; these debates implied whether already existing reading skills in the first language are sufficient or a minimum threshold in the foreign language is required (Alderson, 1984). As a matter of fact, the compensatory model of reading reveals that half of the reading comprehension encompasses first language (L1) literacy and second language (L2) knowledge; while, the remaining part embarks unexplained variance, which is idiosyncratic involving, for instance, engagement, gender, and interest (Bernhardt, 2011)

Both gender and interest may deem important in EFL reading comprehension. Restricted with particular beliefs and perceptions about gender stemming from their cultural background, EFL male and female students' reading comprehension and interest are characterized by variation (Deckert, 2004). In other words, bringing mental representations and background knowledge together may ascribe schema as an explanation of gender variation in L2 reading of genderoriented passages (Brantmeier, 2001). The latter also account for gender variation in reading (Maehara, 2010). Furthermore, due to gender variation in background information and interest, the topic of reading passages is relatively affecting EFL students' reading comprehension (Bugel \& Buunk, 1996).

Regarding schema as linguistic, formal, and content (Hedgcock \& Ferries, 2009), part of research in gender and EFL reading considered interest and background knowledge as distinct with respect to the impact of passage-orientation. (Bugel \& Buunk, 1996); similarly, other researchers implemented multi-component models of interest, including perceived (PI) and situational interest (SI), yet those models were for L1 (Ainley, Hillman \& Hidi, 2002) or without taking into account gender differences in EFL and L2 reading (Brantmeier, 2006).

In addition, EFL first year university students at the University of Algiers2 may come with various perceptions and attitudes acquired from reading EFL texts in the secondary school textbook in Algeria. To enable students to develop intercultural communicative competence, the reading texts include culture-specific and global themes (Rezig, 2015). Moreover, gender variance is at a glance for not only at the secondary school texts, but also for teaching-learning processes and classroom interaction (Maehara, 2010). In this way, gender differences in reading comprehension might be prevalent among university students (Brantmeier, 2003). These differences, in turn, can be explained by interest (Carrell \& Wise, 1998).

This study provides clear insights about EFL students' individual differences in reading comprehension tasks. It examines previous assumptions about linking foreign language reading to the language proficiency level. Drawing upon this claim, this study attempts to explain why males and females differ in EFL RC, and what are the factors accounting for any possible variance. In this concern, five research questions were formulated as follows:

a) Are there gender differences in EFL students' reading comprehension of gender-oriented passages?

b) Are there gender differences in EFL students' situational interest cross gender-oriented passages? 
c) Are there gender differences in EFL students' perceived interest across gender-oriented passages?

d) Do gender differences in EFL students' situational interest explain gender differences in EFL students' reading comprehension?

e) Do gender differences in EFL students' perceived interest explain gender differences in EFL students' reading comprehension?

The aim of this study, then, is to investigate gender differences in EFL students' reading comprehension while reading various gender-oriented passages, and it explores whether PI and SI account for any gender differences in the students' reading comprehension.

\section{Literature Review \\ Gender and Reading Comprehension}

Owing to the linguistic threshold and short-circuit hypotheses, debates on whether language proficiency in foreign language or gender affects reading comprehension have been sustaining (Brantmeier, 2003). For the linguistic threshold hypothesis advocators, Bugel and Buunk (1996) asserted that language proficiency is worth considering than gender since the first is necessary in early stages of learning, while, background knowledge may account for gender variance in advanced stages; yet, in the interactive compensatory model, all factors including gender, contextual factors, and background knowledge contribute together to facilitate comprehension (Bernhardt, 2011).

Reading researchers can control and measure variables other than linguistic knowledge, in terms of background and cultural knowledge of the language learned (Alderson, 2000). This complies with earlier views of Rumelhart (1980), confirming the variation of schemata possessed by individuals which are constantly changing and modifying. Likewise, Carrell (1987) concluded that schema and background knowledge are similar as long as the reader acquires content schema for ideas and information and formal schema, related to the pattern of organization of texts.

In studies exploring gender, reading comprehension and background knowledge, interest, and gender-orientation of passages appear as indispensable aspects to examine for their potential impact (Brantmeier, 2003). Therefore, the possible explanation of gender variation in EFL reading may be schema theory. In few words, texts with different gender orientations launch schemata related to the reader's interest, facilitating or debilitating the process of comprehension (Bugel \& Buunk, 1996).

\section{Passage Content}

According to schema theory, a reader affords prior knowledge peculiar to the text (Rumelhart, 1980). In other words, knowledge structures, formal and content schemata are brought by the reader for the macrostructures and content domains of texts (Carrell, 1987). More notably, the gender of readers with texts of different gender orientations tend to reveal significant interactions with reading comprehension (Brantmeier, 2001)

Accordingly, previous researches considering schema theory have shown gender differences in reading comprehension owing to passage content. Bugel and Buunk (1996) examined gender differences in reading among EFL learners using neutral, male- and female-oriented passages, 
which encompass various topics and genres. Findings indicated males outperformed in tests containing neutral and male-oriented texts, while females achieved higher in female texts. Furthermore, Brantmeier (2003) used a male-oriented passage, a boxing match short story including male characters only, and a female-oriented passage, a short story of a frustrated mother and wife including solely female characters. Confirming the linguistic threshold hypothesis, she concluded that passage content influences male and female comprehension of texts.

\section{Situational and Perceived Interest}

In studies examining gender differences in reading, interest appeared as the possible explanation for any variance owing to gender or passage content. (Brantmeier, 2001; Bugel \& Buunk, 1996). Defining the construct of interest in reading is rather problematic due to previous researches confining it to motivation (Bernhardt, 2011). Nevertheless, Bugel and Buunk (1996) affirmed: social and psychological factors such as motivational constructs and task-specific beliefs seem inadequate for explaining sex differences in FL reading comprehension" (p. 16). On the other hand, some studies regarded interest and content as two categories of motivation (Hidi \& Baird, 1988); while, Hidi (2001) contended that interest increases the motivation to read and can be regarded as distinct from motivation.

First, Kintsch (1980) explained interest in terms of cognitive and emotional proportions as the first is of three components: reader's knowledge of the text content, surprising elements with 'postdictability', cohesion of the text's macrostructure. On the other side, emotional interest refers to the direct feelings aroused by the text's cognitive structures, or the latter are already emotive for readers regardless of the text but accounting for their culture.

Subsequent researches deconstructed interest in reading to situational and individual or personal interest. On the assumption that interest tends to affect reading comprehension, salient factors of SI are task environment, students' self-regulation, and textual features such as ease of comprehension and vividness (Hidi \& Harackiewicz, 2000). On the other hand, individual interest is regarded as enduring traits existing in readers associated with their schemata and opposed to the shortly lasting SI as Alexander (1997) stated: "Individual interest, or personal interest, has been described as an association or a deep-seated investment in a specific topic, object or event (i.e. avocational or vocational pursuits)"(p. 221); in few words, situational and PI are not opposite but related to each other since both of them evolve through exposure to various reading tasks (Hidi, 2001)

Drawing upon schema theory, Bugel and Buunk (1996) argued that passage content accounts for gender differences in EFL reading as learners are acquainted with topics interesting to them. According to them, prior knowledge is related and not contained in interest. They asserted that there are gender differences in interest and prior knowledge of gender-oriented passages; however, in the analysis of covariance, gender differences in reading comprehension were related to prior knowledge and interest, mostly in reading habits. These findings emphasize the role of text topic in gender differences in reading.

Carrell and Wise (1998) supported Bugel' and Buunk's (1996) views on interest and prior knowledge in ESL reading, assuming that these variables can be examined separately. As the 
researchers presumed, there was no relationship between prior knowledge and interest. Males slightly achieved higher than females as the first outperformed in topics they had interest in, but this was not the case for females, who did not achieve higher in topics interesting to them. Likewise, there was a correlation between gender and interest, but no significant effect of gender was found. In addition, there was a significant effect of English proficiency level on reading comprehension.

The previously mentioned empirical researches by Bugel and Buunk (1996) and Carrell and Wise (1998) may be open to criticism. Interest cannot be simply narrowed-down to topic interest to be measured before or after reading. Besides, interest in those studies was kept distinct from background knowledge. However, interest stimulated by the text is just one type of interest, SI (Hidi, 2001). Whereas, the overall feeling apart from the text is individual interest (Hidi \& Baird, 1988); the latter is confined to the individual's schema (Alexander, 1997; Kintsh, 1980). Even SI, referred to as knowledge triggered interest, raises from the interaction between background knowledge and new knowledge of the text (Hidi \& Baird, 1988). Besides, SI contributes significantly in overcoming the students' lacuna in pre-existing individual interest (Hidi \& Harackiewicz, 2000). In other words, through accretion, tuning, and restructuring modes, learners can develop new schemata (Rumelhart, 1980). In this way, students' values, knowledge, and positive affect in particular subjects and texts increase (Hidi \& Baird, 1988; Kintsch, 1980).

Considering the components, situational and individual interests, Schraw, Bruning and Svoboda (1995) suggested a model for measuring SI and PI based on early conceptions of interest. Accordingly, they constructed two questionnaires for these variables. The situational interest questionnaire (SIQ) includes 17 items proceeding factor analysis, and the perceived interest questionnaire (PIQ) contains 10 items.

For SIQ, six categories were labeled as the sources of SI. First, ease of comprehension items indicate to what degree the text was easy to focus on and to recall; the set of questions for prior knowledge retrieves the reader's familiarity with the text information proceeding reading. Cohesion category involves items for clarity and text structure, vividness reporting whether the text is exciting to read; engagement measures the extent to which "the text was thought provoking, stimulating, and timely' (p. 3); lastly, emotiveness reveals any emotional reaction evoked from the reading. In PIQ, the items were measuring issues stemming from the reading and the overall interest in passage content.

Schraw et al. (1995) oncluded that both SI and PI explained variance in text recall, and PI mediates the relationship amid text recall and SI components. Besides, ease of comprehension, vividness, engagement, cohesion yielded significant relationships with PI, but prior knowledge and emotiveness did not. Eventually, they contended that interest is affected by various features of readers and texts. This supported Hidi and Baird's (1988) views on the importance of implementing multiple genres when researching interest in reading.

Using Schraw et al.,'s (1995) inventory in the L2 context, Brantmeier (2006) disregarded vivideness as it interacts with other sources of interest. Moreover, she contended that PI and ease of recollection engagement and cohesion are correlated. She added that PI accounted for the variation in sentence completion and multiple choice tasks only. Once the PI effect had been 
controlled, ease of recollection was significantly correlated with all assessment tasks in contrast to prior knowledge, which had shown no relationship with any task.

There may have been a scarcity of accurate studies discussing gender, interest, and EFL reading. Some studies examined the impact of interest in EFL reading, referring to interest as reading habits and subject choice; while, few research works conceptualized interest in relation to the text topic. However, investigating interest in reading should account for the reader and text variables. These variables may be explored using the perceived situational interest questionnaire. Furthermore, no previous research attempted to explain gender differences in EFL using SIQ, PIQ, and gender-oriented passages.

\section{Methods}

\section{Sample}

The selected sample included 59 undergraduate EFL first-year students at the University of Algiers 2 during the academic year: 2019-2020. Owing to the small ratio of male to female students amid first year students, the sample was conveniently selected, including 24 males and 35 females; their ages' means were respectively (18.6) and (18.8). Age may be deemed a crucial factor triggering interest in reading (Bugel \& Buunk, 1996). It was necessary to control it in this study. These participants received explicit instruction in numerous reading techniques by the same teacher.

\section{Research Tools}

The current research encompassed two tests, which, in turn, included two types of passages: male and female. Besides, two questionnaires of perceived and sources of interest were required in this study.

\section{Reading Comprehension Tests}

Ten multiple choice questions were formulated in each test. The questions were ordered as follows: Two questions for predicting, a question for the general idea, two questions for supporting details, two questions for inferring the meaning of words, two questions for inferences, and one question for summarizing. Each of these questions contains four distracters. The estimated time for responding to the tests was 45 minutes for the first test and 40 minutes for the second.

\section{Reading Passages}

The selected passages for each test were labeled as male- and female-oriented passages. This classification complied with the socio-cultural context of the participants. That is, the occupational roles and sport tasks assigned to males and the domestic roles of females were peculiar to the Algerian context, which were even emphasized at early stages of EFL learning (Abdelhay \& Benhaddouche, 2015). Besides, Porreca's (1984) model was used to evaluate the passages' orientation in tests. It encompasses omission, firstness, masculine generics, occupational roles, and adjectives.

In the first test, the female text was an excerpt from a Mexican novel translated to English entitled "Like Water for Chocolate" by Esquivel (1989). The novel is about cooking, household, and childcare. The text is about a young girl, born prematurely, and her father died. This obliged 
her mother to run their farm and to let another woman take charge of her and teach her cooking. The passage contains 538 words. Four of five characters were female, and no features were referring to masculine generics or firstness. The occupational roles were three, exclusively for female characters; for adjectives, physical appearances were not found, while the remaining sorts were $100 \%$ for females except for intellect/education, an adjective out of four was a male one.

In the second test, the male text was extracted from the conclusion of the book" CRISTIANO AND LEO: The Race to Become the Greatest Football Player of All Time" By Burns (2018). The text is comparison/ contrast with 518 words about Lionel Messi and Cristiano Ronaldo. The characters of the texts were purely males, even the occupational roles with no firstness or masculine generics. In addition, along with the various adjectives, there were no adjectives modifying females. This text may be appealing to males for mentioning a controversial topic in sports about which one is the best footballer.

\section{Sources of Interest Questionnaire}

The questionnaire of the sources of interest, SI, was adapted from Brantmeier's (2006) questionnaire. Three questionnaires were designed for each reading comprehension test. Each questionnaire contains 16 items dispersed along with five categories, namely cohesion four items, prior knowledge three items, engagement three items, ease of recollection four items and, emotiveness three items. Also, some changes were made for the second and third questionnaires, which were respectively for male and neutral passages as the word "story" was substituted by "text".

Piloting this questionnaire yielded some wording issues. Thus, item four in cohesion was restated as follows: "The text/story had a refined style", and item two in prior knowledge became: "The information in the story/ text were well known to me". In engagement, item one was changed to "The text/story made me thoughtful", and the term "relevant" in item two was turned into "important". Lastly, the word "eeriness" of the third item in emotiveness was changed into "creepiness".

\section{Perceived Interest Questionnaire}

The questionnaire of perceived interest was adapted too from Brantmeier's (2006) questionnaire. For each reading comprehension test, a questionnaire was administered to the participants. Each questionnaire includes nine Likert scale items from "Strongly Disagree" to "Strongly Agree". Slight changes took place preceding the administration of the questionnaire. In item eight, English was written instead of Spanish, and for all items, the word "story" was changed into "text" for the tests including male and neutral passages. Furthermore, pilot testing was conducted, revealing a problem with wording for item nine. Thus, the latter became as follows: "This story really attracted my attention.".

\section{Procedure and Methods of Analysis}

The study took place in the second half of February 2020. This period was congruent with the second week of the second semester. Along that period, students received instruction in the reading strategies being investigated in the reading comprehension tests. In addition, the two questionnaires of SI and PI were fused as one questionnaire since it would be difficult for participants to understand the multiple components of interest. 
Time sequences were of paramount importance during the administration of the tests and the questionnaires. The administration of the tools lasted three hours, including short breaks between each phase, comprising one of the tests with their questionnaires. It was indispensable to administer the corresponding questionnaires directly once the participants had finished any test.

After the tools' administration, data was inserted in SPSS 26.0 for analysis, and the total scores for each test were put in separate columns. Besides, for each category in the questionnaires, variables were computed. Then, means scores of males and females in the tests and the questionnaires' categories were computed separately, yet the standard deviation was not computed since there would be another measure of spread, the sum of squares, in subsequent analysis for the same data.

Analysis of variance (ANOVA) was fulfilled for the tests, PI and SI questionnaires data to find out whether the results significantly differ across genders. After that, an analysis of covariance (ANCOVA) would reveal whether gender differences in the SI and PI, if any, as covariates can explain any variance in male and female participants' reading scores in the two tests.

\section{Results}

\section{Gender Differences in EFL Reading Comprehension}

Analysis of reading comprehension tests' scores yielded distinct findings for both female and male participants either in descriptive statistics or in the analysis of variance. Computing the means and the standards of deviation of both genders revealed the following results.

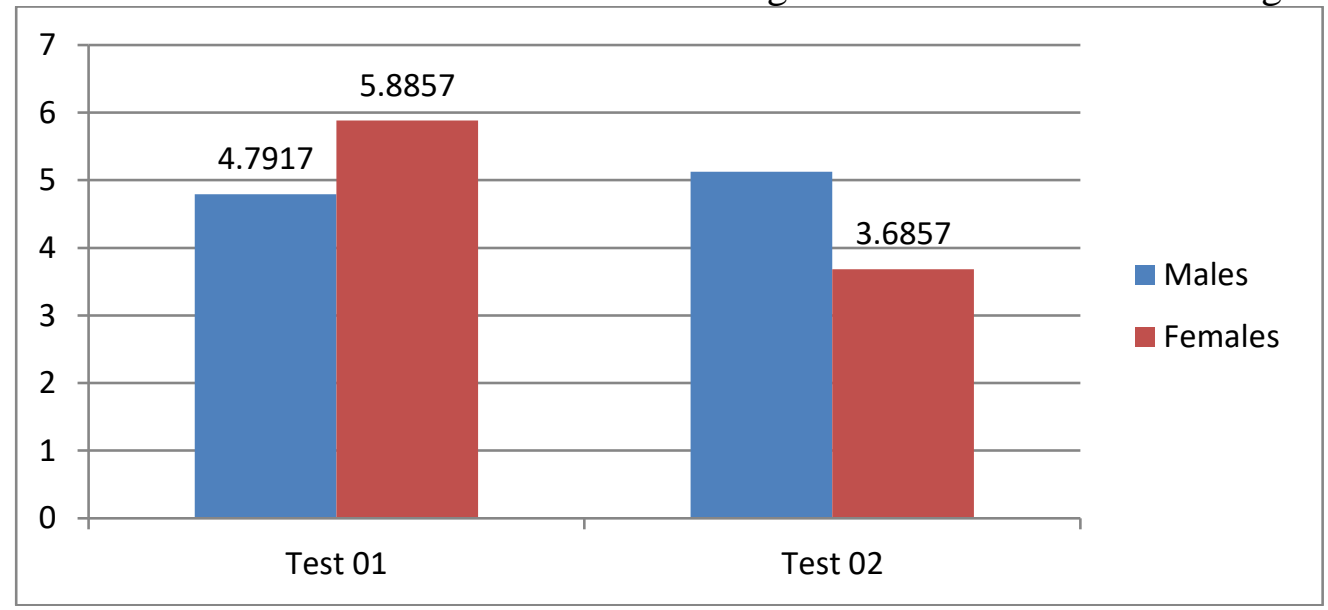

Figure 1. Average scores of males and females in reading comprehension tests

In the first reading comprehension test, female participants outperformed with an average score (5.88), compared to males who scored (4.97); in the second reading comprehension test, the difference between male and female scores was clearly viewed as the first mean was (5.12) and the second (3.68).

To ensure whether the previous differences in the tests are significant, a one-way analysis of variance (ANOVA) took place, yielding these results. 
Arab World English Journal (AWEJ) Volume 12. Number 1. March 2021

The Effects of Situational and Perceived Interest on EFL Reading

Akhrib \& Nedjai

Table 3. Analysis of variance for males and females ' reading comprehension

\begin{tabular}{|c|c|c|c|c|c|c|}
\hline \multicolumn{7}{|c|}{ ANOVA } \\
\hline \multirow{2}{*}{ Test01 } & $\begin{array}{c}\text { Sum of } \\
\text { Squares }\end{array}$ & df & Mean Square & F & Sig. \\
\hline & Between Groups & 17,041 & 1 & 17,041 & 4,056 &, 049 \\
\cline { 2 - 8 } & Within Groups & 239,501 & 57 & 4,202 & & \\
\cline { 2 - 8 } & Total & 256,542 & 58 & & & \\
\hline \multirow{2}{*}{ Test02 } & Between Groups & 29,493 & 1 & 29,493 & 10,629 &, 002 \\
\cline { 2 - 8 } & Within Groups & 158,168 & 57 & 2,775 & & \\
\cline { 2 - 8 } & Total & 187,661 & 58 & & & \\
\hline
\end{tabular}

Analysis of variance for male and female participants' reading comprehension scores demonstrated significant differences in the first and second tests. In the first test, the differences of the mean squares between groups were relatively high over within groups with an F statistics (4.056), yielding a p-value $(.049)<(.05)$. In the second test, the F statistics value was even higher $(10,629)$ with a p-value $(.002)<(.05)$.

\section{Gender Differences in Situational and Perceived Interest}

Analysis of the questionnaires of PI and SI for each reading passage demonstrated inconsistent results of which the means of male and female participants' responses were computed along with the categories of each questionnaire. For the first questionnaires, results were shown in the figure 2.

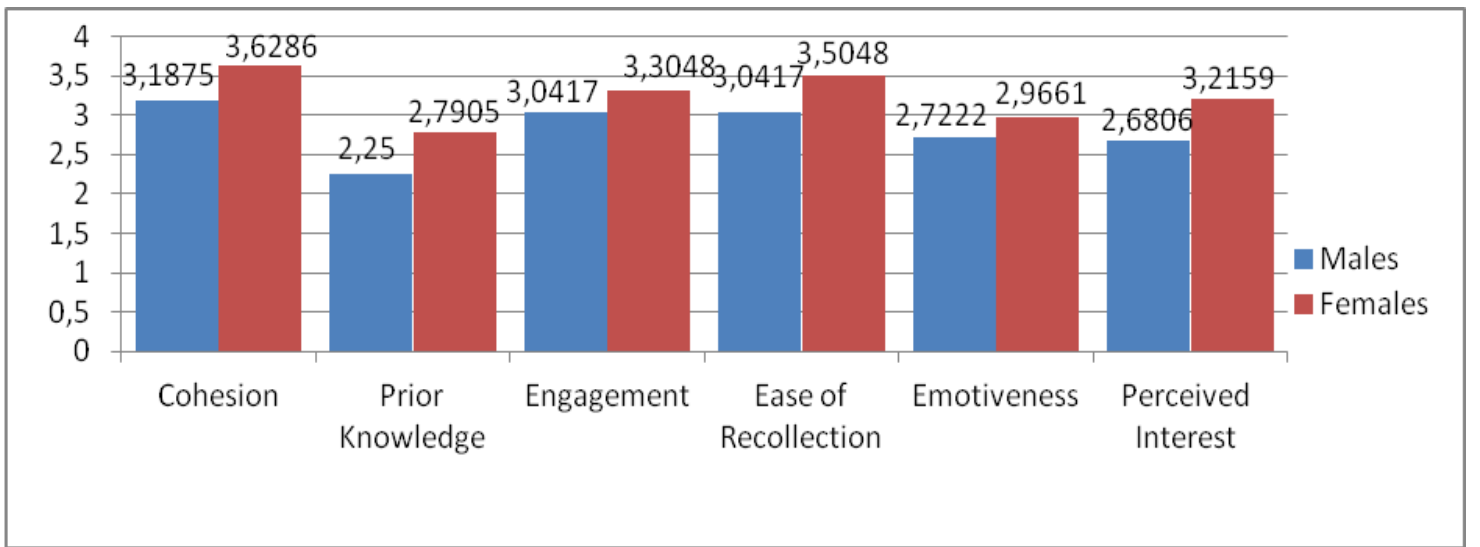

Figure 2. Male and female participants' mean scores in situational and perceived interest questionnaires one.

Regarding the SI means, differences were found between males and females except for engagement in which the difference is slight with (3.04) for males and (3.30) for females. Furthermore, females indicated high degrees in cohesion, prior knowledge, and ease of recollection, yet the difference was trivial in emotiveness with (2.96) for females and (2.72) for males. For PI, females scores (3.21) were higher than males (2.69). In few words, gender differences in SI save engagement and PI related to the female text were higher amid female participants. 
Arab World English Journal (AWEJ) Volume 12. Number 1. March 2021

The Effects of Situational and Perceived Interest on EFL Reading

Akhrib \& Nedjai

Similarly, ANOVA confirmed the previous results found in mean computing. The table below unveils the ANOVA for gender differences in the second questionnaires of SI and PI.

Table 4. Analysis of variance for males and females' situational and perceived interest one

\begin{tabular}{|c|c|c|c|c|c|c|}
\hline \multicolumn{7}{|c|}{ ANOVA } \\
\hline & & $\begin{array}{l}\text { Sum of } \\
\text { Squares }\end{array}$ & df & $\begin{array}{c}\text { Mean } \\
\text { Square }\end{array}$ & $\mathrm{F}$ & Sig. \\
\hline \multirow[t]{3}{*}{$\begin{array}{c}\text { Cohesion_female } \\
\text { text }\end{array}$} & $\begin{array}{l}\text { Between } \\
\text { Groups }\end{array}$ & 2,770 & 1 & 2,770 & 4,884 & ,031 \\
\hline & Within Groups & 32,328 & 57 & ,567 & & \\
\hline & Total & 35,097 & 58 & & & \\
\hline \multirow[t]{3}{*}{$\begin{array}{l}\text { Priorknowle_ } \\
\text { femaletext }\end{array}$} & $\begin{array}{c}\text { Between } \\
\text { Groups }\end{array}$ & 4,159 & 1 & 4,159 & 4,066 & ,048 \\
\hline & Within Groups & 58,297 & 57 & 1,023 & & \\
\hline & Total & 62,456 & 58 & & & \\
\hline \multirow[t]{3}{*}{$\begin{array}{l}\text { Engagement_ } \\
\text { femaletext }\end{array}$} & $\begin{array}{c}\text { Between } \\
\text { Groups }\end{array}$ & 3,164 & 1 & 3,164 & 4,133 & ,047 \\
\hline & Within Groups & 43,638 & 57 & ,766 & & \\
\hline & Total & 46,802 & 58 & & & \\
\hline \multirow[t]{3}{*}{$\begin{array}{c}\text { Easeofrecollection } \\
\text { _ femaletext }\end{array}$} & $\begin{array}{c}\text { Between } \\
\text { Groups }\end{array}$ & 3,053 & 1 & 3,053 & 4,643 & ,035 \\
\hline & Within Groups & 37,485 & 57 & ,658 & & \\
\hline & \begin{tabular}{|l|} 
Total \\
\end{tabular} & 40,539 & 58 & & & \\
\hline \multirow[t]{3}{*}{$\begin{array}{c}\text { Emotiveness_ } \\
\text { femaletext }\end{array}$} & $\begin{array}{c}\text { Between } \\
\text { Groups }\end{array}$ &, 010 & 1 & ,010 &, 025 & ,874 \\
\hline & Within Groups & 21,119 & 56 & ,377 & & \\
\hline & Total & 21,128 & 57 & & & \\
\hline \multirow[t]{3}{*}{$\begin{array}{l}\text { PerceivedInterest__ } \\
\text { femaletext }\end{array}$} & $\begin{array}{l}\text { Between } \\
\text { Groups }\end{array}$ & 4,080 & 1 & 4,080 & 4,269 & 043 \\
\hline & Within Groups & 54,475 & 57 & ,956 & & \\
\hline & Total & 58,555 & 58 & & & \\
\hline
\end{tabular}

Significant gender differences were found in some SI as in cohesion (F: 4.884; sig. 0.031), prior knowledge (F: 4.066; sig .048), engagement (F: 4.133; sig .047), and ease of recollection (F: 4.643; sig .035), yet gender variance was not significant in emotiveness (.874) owing to its $\mathrm{F}$ statistics, which was (.025). These values report that differences between males and females in engagement and emotiveness are mostly null. In PI, differences among males and females were high with F-statistics (4.269), yielding a significant p-value (.043).

In the second set of questionnaires of SI and PI for the male-oriented passage, differences were found in the mean scores of male and female participants. 


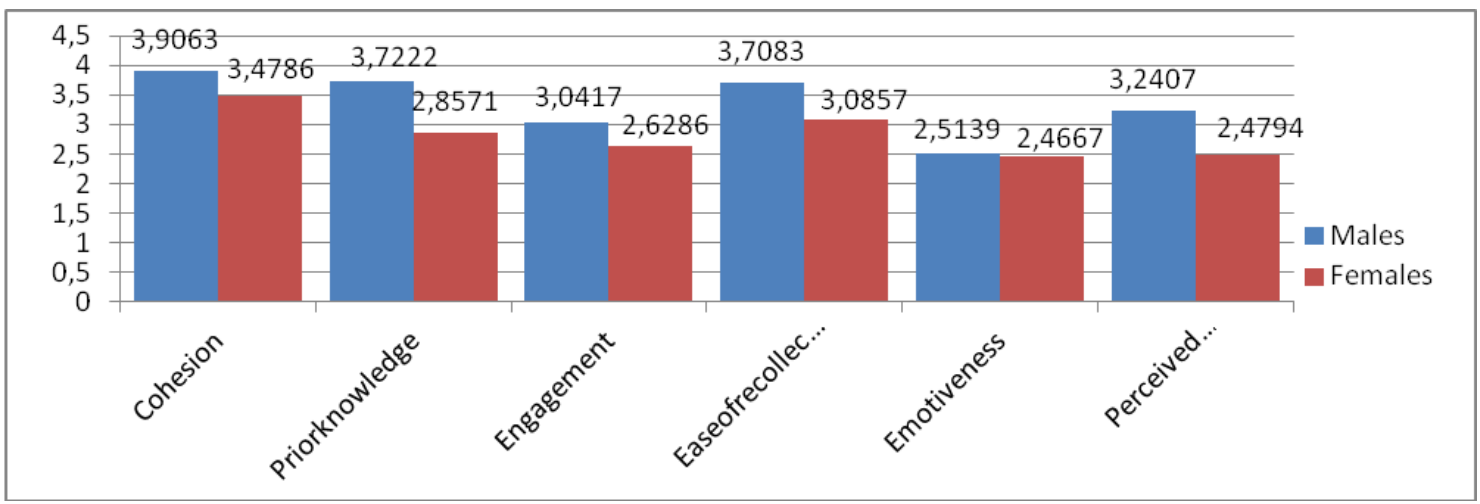

Figure 3. Male and female participants' means in situational and perceived interest questionnaires two

The mean values of males and females were distinct in SI and PI. Differences were high in cohesion, prior knowledge, and ease of recollection, yet findings in engagement did not reveal high differences as males' mean was (3.04) and females (2.62). Besides, emotiveness means were almost close wherein males' average was (2.51), and females indicated (2.46). In PI, male participants' mean was elevated higher than females as the first was (3.24) and the former (2.47).

ANOVA findings comply to a large extent with means comparison based on gender.

Table 5. Analysis of variance for males and females' situational and perceived interest 02

\begin{tabular}{|c|c|c|c|c|c|c|}
\hline \multicolumn{2}{|c|}{ ANOVA } & $\begin{array}{c}\text { Sum of } \\
\text { Squares }\end{array}$ & df & $\begin{array}{c}\text { Mean } \\
\text { Square }\end{array}$ & F & Sig. \\
\hline \multirow{2}{*}{ Cohesion_maletext } & Between Groups & 2,604 & 1 & 2,604 & 8,850 & .004 \\
\cline { 2 - 7 } & Within Groups & 16,773 & 57 &, 294 & & \\
\cline { 2 - 8 } & Total & 19,377 & 58 & & & \\
\hline \multirow{3}{*}{$\begin{array}{c}\text { Priorknowledge_ } \\
\text { maletext }\end{array}$} & Between Groups & 10,655 & 1 & 10,655 & 8,039 & .006 \\
\cline { 2 - 8 } & Within Groups & 75,545 & 57 & 1,325 & & \\
\cline { 2 - 8 } & Total & 86,200 & 58 & & & \\
\hline \multirow{2}{*}{$\begin{array}{c}\text { Engagement_ } \\
\text { maletext }\end{array}$} & Between Groups & 2,430 & 1 & 2,430 & 3,461 & .068 \\
\cline { 2 - 8 } & Within Groups & 40,019 & 57 &, 702 & & \\
\cline { 2 - 8 } & Total & 42,448 & 58 & & & \\
\hline $\begin{array}{c}\text { Easeofrecollection } \\
\text { maletext }\end{array}$ & Between Groups & 5,519 & 1 & 5,519 & 7,055 & .010 \\
\cline { 2 - 8 } & Within Groups & 44,590 & 57 &, 782 & & \\
\cline { 2 - 8 } & Total & 50,109 & 58 & & & \\
\hline \multirow{2}{*}{$\begin{array}{c}\text { Emotiveness_ } \\
\text { maletext }\end{array}$} & Between Groups &, 032 & 1 &, 032 &, 100 & .753 \\
\cline { 2 - 8 } & Within Groups & 18,040 & 57 & & & \\
\cline { 2 - 8 } & Total & 18,072 & 58 & & & \\
\hline \multirow{2}{*}{$\begin{array}{c}\text { Perceivedinterest_ } \\
\text { maletext }\end{array}$} & Between Groups & 8,253 & 1 & 8,253 & 11,139 & .001 \\
\cline { 2 - 8 } & Within Groups & 42,233 & 57 &, 741 & & \\
\cline { 2 - 8 } & Total & 50,486 & 58 & & & \\
\hline
\end{tabular}

ANOVA for SI yielded significant differences by gender in cohesion (F: 8.850; sig .004), prior knowledge (F: 8.039; sig .006), and ease of recollection (F: 7.055; sig .010). Although engagement results demonstrated a considerable difference owing to the high F statistics (3.461), 
this difference was not significant as the p-value was (.068); besides, similar to previous findings, no difference was found in emotiveness as the F value was (.100), with a low level of significance (.753). In PI, the F value was (11.139) yielded a p-value (.001). This indicates a significant variance by gender.

\section{Gender Differences in SI and PI Accounting for Gender Variance in EFL Reading}

Considering the ANOVA for the SI and PI questionnaires, the ANCOVA revealed whether variance in reading comprehension was caused by gender differences in SI and PI. In this concern, it would include PI alone and categories of SI indicating gender differences in terms of cohesion, prior knowledge, engagement, and ease of recollection for the female passage as well as cohesion, prior knowledge, and ease of recollection for the male text. Thus, ANCOVA for the effect of these categories on reading comprehension by gender for the female text appears as follows

Table 7. Analysis of covariance of situational interest effect on reading by gender- test 01

\begin{tabular}{|c|c|c|c|c|c|}
\hline \multicolumn{7}{|c|}{ Tests of Between-Subjects Effects } \\
\hline $\begin{array}{c}\text { Type III Sum } \\
\text { of Squares }\end{array}$ & df & Mean Square & F & Sig. \\
\hline Corrected Model & $11,887^{\text {a }}$ & 4 & 2,972 &, 813 &, 527 \\
\hline Intercept & 6,741 & 1 & 6,741 & 1,844 &, 185 \\
\hline Cohesion_femaletext &, 824 & 1 &, 824 &, 225 &, 638 \\
\hline $\begin{array}{c}\text { Priorknowledge_femalete } \\
\text { xt }\end{array}$ &, 947 & 1 &, 947 &, 259 &, 614 \\
\hline $\begin{array}{c}\text { Engagement_femaletext } \\
\text { Easeofrecollection_femal } \\
\text { etext }\end{array}$ & 3,588 & 1 & 3,588 &, 982 &, 330 \\
\hline $\begin{array}{c}\text { Gender } \\
\text { Error }\end{array}$ & 7,580 & 1 & 7,580 & 2,074 &, 160 \\
\hline $\begin{array}{c}\text { Total } \\
\text { Corrected Total }\end{array}$ & 109,656 & 30 & 3,655 & &. \\
\hline R Squared =,098 (Adjusted R Squared = -,022) & & & \\
\hline \multicolumn{7}{|c|}{1334,000} & 35 & & & \\
\hline a. & 121,543 & 34 & & & \\
\hline
\end{tabular}

The R squared is almost null (.098), indicating that all the variables included in the corrected model depict very few sum of squares compared to the error sum of squares (109.656). Besides, the F statistics and level of significance in cohesion (F: .225; sig .638), prior knowledge (F: 259; sig .614), engagement (F: .982; sig .330), and ease of recollection (F: 2.074; sig .160) revealed no effect of these variables on gender differences in reading comprehension of the first test. Thus, gender differences in those sources of interest did not account for gender variation in the first test.

ANCOVA for PI effect on gender differences in reading comprehension for the first test yielded the following results 
Arab World English Journal (AWEJ) Volume 12. Number 1. March 2021

The Effects of Situational and Perceived Interest on EFL Reading

Akhrib \& Nedjai

Table 8. Analysis of covariance for perceived interest effect on reading by gender-test 01

\begin{tabular}{|c|c|c|c|c|c|}
\hline \multicolumn{7}{|c|}{ Tests of Between-Subjects Effects } \\
\hline & $\begin{array}{c}\text { Type III } \\
\text { Sum of } \\
\text { Squares }\end{array}$ & df & Mean Square & F & Sig. \\
\hline Source & $7,302^{\mathrm{a}}$ & 1 & 7,302 & 2,109 &, 156 \\
\hline Corrected Model & 62,179 & 1 & 62,179 & 17,961 &, 000 \\
\hline Intercept & 7,302 & 1 & 7,302 & 2,109 &, 156 \\
\hline $\begin{array}{c}\text { PerceivedInterest_femalet } \\
\text { ext }\end{array}$ &, 000 & 0 &. &. &. \\
\hline Gender & 114,240 & 33 & 3,462 & & \\
\hline Error & 1334,000 & 35 & & & \\
\hline Total & 121,543 & 34 & & & \\
\hline \multicolumn{2}{c}{ Corrected Total } & 34 & & & \\
\hline a. R Squared =,060 (Adjusted R Squared =,032) & & & \\
\hline
\end{tabular}

The sum of squares type III of PI was slight (7.302) compared to the total sum of squares (1334.0). This could explain the R squared value (.060), indicating that the error sum of squares was high (114.240). Furthermore, the F statistics of PI was (2.109), revealing a low level of significance (.156). In this way, gender differences in PI did account for gender differences in reading comprehension of the female text.

ANCOVA for the effect of cohesion, prior knowledge, and ease of recollection by gender on variation in reading comprehension of the second test demonstrated similar results in the first test.

Table 9. Analysis of covariance of situational interest effect on reading by gender- test 02

\begin{tabular}{|c|c|c|c|c|r|}
\hline \multicolumn{7}{|c|}{ Tests of Between-Subjects Effects } \\
\hline & $\begin{array}{c}\text { Type III } \\
\text { Sum of } \\
\text { Squares }\end{array}$ & df & $\begin{array}{c}\text { Mean } \\
\text { Square }\end{array}$ & F & Sig. \\
\hline Source & $30,610^{\text {a }}$ & 4 & 7,652 & 2,631 &, 044 \\
\hline Corrected Model & 23,324 & 1 & 23,324 & 8,020 &, 006 \\
\hline Intercept &, 334 & 1 &, 334 &, 115 &, 736 \\
\hline Cohesion_maletext &, 753 & 1 &, 753 &, 259 &, 613 \\
\hline $\begin{array}{c}\text { Priorknowledge_male } \\
\text { text }\end{array}$ &, 001 & 1 &, 001 &, 000 &, 984 \\
\hline $\begin{array}{c}\text { Easeofrecollection_ } \\
\text { maletext }\end{array}$ & 22,196 & 1 & 22,196 & 7,632 &, 008 \\
\hline Gender & 157,051 & 54 & 2,908 & & \\
\hline Error & 1264,000 & 59 & & & \\
\hline Total & 187,661 & 58 & & & \\
\hline Corrected Total & & & & & \\
\hline R Squared & & & & & \\
\hline
\end{tabular}

a. $\quad$ R Squared $=, 163$ (Adjusted R Squared $=, 101$ ) 
The R Squared value (.136) indicated that the residual sum of squares was less than the total sum of squares type III since the error sum of squares type III was even higher than the corrected model. That is, cohesion, prior knowledge, and ease of recollection did not explain the variation in gender in the reading comprehension test 02 , not to mention the intercept variable with a high mean square (23.324) yielding a significant p-value (.006). In addition, there is no perceived impact of the differences in the categories of the SI on gender differences in reading as their $\mathrm{F}$ statistics and p-values were as follows: cohesion (F: .115; sig .736), prior knowledge ( F: .259; sig .613) and ease of recollection (F: .000; sig .984).

ANCOVA for the impact of gender differences in PI in the male text on gender differences in reading comprehension revealed no significant of effect of gender variation in PI on gender differences in reading.

Table 10. Analysis of covariance for perceived interest effect on reading by gender- test 02

\begin{tabular}{|c|c|c|c|c|c|}
\hline \multicolumn{7}{|c|}{ Tests of Between-Subjects Effects } \\
\hline \multicolumn{7}{|c|}{ Dependent Variable: Test02 } & & \\
\hline Source & $\begin{array}{c}\text { Type III Sum } \\
\text { of Squares }\end{array}$ & df & Mean Square & F & Sig. \\
\hline Corrected Model & $33,770^{\mathrm{a}}$ & 2 & 16,885 & 6,144 &, 004 \\
\hline $\begin{array}{c}\text { Intercept } \\
\begin{array}{c}\text { Perceivedinterest_malete } \\
\text { xt }\end{array}\end{array}$ & 57,831 & 1 & 57,831 & 21,044 &, 000 \\
\hline $\begin{array}{c}\text { Gender } \\
\text { Error }\end{array}$ & 17,064 & 1 & 4,277 & 1,556 &, 217 \\
\hline Total & 153,891 & 56 & 2,748 & &, 016 \\
\hline Corrected Total & 1264,000 & 59 & & & \\
\hline a. R Squared =,180 (Adjusted R Squared =,151) & & & \\
\hline
\end{tabular}

The type III sum of squares of PI was trivial (4.277) compared to the error sum of squares (153.891), and the R squared was (.180). This means that PI did not explain the variation in reading comprehension. Besides, F statistic of PI (1.556), yielding (.217) level of significance. In few words, gender variance in PI did not cause gender differences in reading comprehension.

\section{Discussion}

Findings in this study yielded gender differences in the reading comprehension tests and in SI and PI for the passages of those tests. Moreover, ANCOVA has been used to examine whether any potential gender variance in SI and PI of the passages account for gender differences in their respective tests.

Using multiple-choice tasks, males and females' achievement differ significantly in reading tests containing female and male passages. Similarly, Brantmeier (2003) affirmed that there were gender differences in multiple-choice reading tests for L2, including male- and female-oriented passages; Besides, the current study findings comply to some degree with Bugel and Buunk's (1996) results, in which males outperformed in male texts, while, females achieved in five out of six female texts; however, in Carrell and Wise's (1998) research, ANOVA revealed no 
significant effect of gender on ESL reading comprehension as males slightly achieved higher than females across texts including topics interesting either for male or for female students.

Measuring interest using SI and PI questionnaires for each passage in the tests demonstrated partial consistent results. Gender differences were significant in cohesion, prior knowledge, ease of recollection, and PI in both female and male texts and engagement for the female passage too; the findings for these passages confirm Hidi's (2001) assumptions about the evolving nature of SI and PI across various texts. Furthermore, emotiveness was not affected by gender in the three passages, meaning that the texts tend not to be evoking emotional impact on both female and male readers. Therefore, legibility, genre, and appropriateness, as suggested by Carrell and Wise (1998), may not solely account for gender differences in SI.

On the other hand, Bugel and Buunk (1996), using another measure of prior knowledge and interest, pointed out significant gender differences in the gender-oriented passages, with high rates of females in female passages. Accounting for the schema theory, it can be suggested that both genders developed particular schemata for female and male passages. These findings confirm Brantmeier (2001; 2003) and Bugel and Buunk's (1996) assumptions about the relationship between schema and interest in reading.

The findings in SI and PI questionnaires lead to reconsider the selection criteria of genderoriented passages in EFL contexts, although this study adhered to Brantmeier (2003), who selected two texts based on characters, male or female, and of what may be specific for each gender such as boxing match and housewives. Using one item, her results comply with the findings for the female and male passages. For instance, both females and males had high means in SI and PI for their respective passages. In this concern, the use of Porreca's (1984) model resulted a relevant selection of gender-oriented passages.

Moreover, participants tended to indicate expected attitudes in this study owing to their early stages of EFL learning in which specific gender roles such as household and cooking for females and sports for males had been instilled in learners through middle school textbooks (Abdelhay \& Benhaddouche, 2015). Accordingly, in addition to to Porreca's (1984) model, Carrell and Wise's (1998) selection of passages according to ratings of males and females should be reconsidered in this case since those ratings also indicate a high correlation with gender and including as well reading habits as in Bugel and Buunk's (1996) research.

ANCOVA included only cohesion, prior knowledge, ease of recollection, and PI for the female and male texts in addition to engagement of the female passage. It indicated that gender differences in those factors and variables did not affect gender differences in their respective reading comprehension tests; nevertheless, Brantmeier (2003) concluded that gender differences in interest account for gender differences in L2. Likewise, Bugel and Buunk (1996) asserted that gender differences in all EFL reading comprehension tests were due to gender differences in prior knowledge and interest.

Carrell and Wise's (1998) study might unfold consistent findings with the current research. Gender, prior knowledge and topic interest significantly interact; they, in turn, did not affect reading comprehension. Instead, language proficiency had the major impact on reading 
comprehension. Attempting to explain the variance in reading comprehension by gender, more variables should be considered in terms of familiarity (Brantemeier, 2003; 2001) and language proficiency. Besides, more factors in SI should be regarded, such as task environment (Hidi \& Harackiewicz, 2000). Expanding the type of tasks in the tests to written recall and sentence recall may evoke different results similar to ANCOVA in Brantmeier's study (2003).

\section{Limitations and Future Research}

Regarding the mean squares for ANOVA or ANCOVA, the mean square for within groups includes few degrees of freedom (59-1), which might affect the accuracy of the results as the categories were (2-1) for the mean square between groups. Another aspect to point out is the choice of tasks, which was narrowed to multiple-choice questions; this limits the scope of inquiry. Indeed, other tasks such as written recall or sentence completion might yield different results since they differ in approach, process versus product.

Any further research should reutilize Porreca's (1984) model in text selection and consider familiarity with students' language proficiency level, and exploring topic as well as genre preferences, appropriateness, and legibility of texts taking into account gender before administering any reading test are of paramount importance. Moreover, varying tasks such as multiple-choice questions, written recall, and sentence completion tends to promote validity for any future research. At last, more research should include large samples with an accepted ratio of male to female participants.

\section{Conclusion}

EFL reading is characterized by complexity. It embraces a wide range of variables, which may have an impact on readers' achievement. In foreign language reading, many variables are part of unexplained variability such as gender and interest (Bernhardt, 2011). This study investigated gender differences in EFL reading comprehension with SI and PI in gender-oriented passages. It also examined the effects of the variations in SI and PI over gender differences in reading comprehension.

There were gender differences in EFL students' reading comprehension of male and female texts in multiple-choice tasks. When Porreca's (1984) model had been deployed in the selection of gender-oriented passages in tests, significant gender differences were found in cohesion, prior knowledge, ease of recollection, and PI for both female and male text, as engagement for female text. In this way, text selection based on Porreca's (1994) content analysis evokes high interest in EFL students.

Gender variance in the first and second reading comprehension tests was not due to gender differences in factors of SI and PI of their passages. Furthermore, the triggered schemata related to those texts did not affect reading comprehension. This may raise many questions about what would account for gender variation in reading comprehension. In addition, familiarity with the text genre and participants' proficiency level were disregarded although a pilot testing was conducted for the tests, which included glosses for difficult words. 
Arab World English Journal (AWEJ) Volume 12. Number 1. March 2021

The Effects of Situational and Perceived Interest on EFL Reading

Akhrib \& Nedjai

About the Authors:

Mohammed Akhrib is a Ph.D. candidate in Applied Linguistics and Teaching English as a Foreign Language at the University of Algiers 2, Algeria. His areas of interest are teaching English as a foreign language, gender, EFL reading comprehension and Affect in EFL learning ORCID: https://orcid.org/0000-0001-9487-4777

Dr. Fatma Zohra Mebtouche Nedjai is a professor in Language Sciences and a lecturer at the High School of Fine Arts of Algiers. Her fields of interest are EFL, Linguistic Anthropology, Language and Gender, Translation Studies, and Arts

\section{References}

Abdelhay, B \& Benhaddouche, W. (2015). Gender stereotyping through textbook illustrations: A case study of algerian middle school textbook- Spotlight on English 1. Mediterranean Journal of Social Sciences, 6(5), 435-440. Doi:10.5901/mjss.2015.v6n5p435

Ainley, M, Hillman, K, Hidi, S. (2002). Gender and interest processes in response to literary texts: Situational and individual interest. Learning and Instruction, 12, 411-428. https://doi.org/10.1016/S0959-4752(01)00008-1

Alderson, J, C. (2000). Assessing reading. New York: CUP.

Alderson, J. C. (1984). Reading in a foreign language: a reading or a language problem? In J. C. Alderson \& A. H. Urquhart (Eds.), Reading in a foreign language (pp. 1-24). London:

Longman.

Alexander, P. A. (1997). Mapping the multidimensional nature of domain learning: The interplay of cognitive, motivational, and strategic forces. In P. R. Pintrich \& M. L. Maehr (Eds.), Advances in motivation and achievement (Vol. 10, pp. 213150). Greenwich, CT: JAI Press.

Bernard, J \& Lee, L. (2004). Select reading: Upper-intermediate. New York. OUP

Bernhardt, E, B. (2011). Understanding advanced second language reading. New York. Routledge.

Brantmeier, C. (2001). Second language reading research on passage content and gender: Challenges for the intermediate-level curriculum. Foreign Language Annals, 34 (4), 325-333. DOI: $10.1111 / \mathrm{j} .1944-9720.2001 . t b 02064 . \mathrm{x}$

Brantmeier, C. (2003). Does gender make a difference? Passage content and comprehension in second language reading. Reading in a Foreign Language, 15(1), 1-27. Retrieved on July $15^{\text {th }}$, 2020, from http://nflrc.hawaii.edu/rfl/April2003/brantmeier/brantmeier.html

Brantmeier, C. (2006). Toward a multicomponent model of interest and L2 reading:Sources of interest, perceived situational interest, and comprehension. Reading in a Foreign Language, 18 (2), 89- 115 . Retrieved on July $15^{\text {th }}, 2020$, from https://nflrc.hawaii.edu/rfl/October2006/brantmeier/brantmeier.pdf

Bugel, K \& Buunk, B, P. (1996). Sex differences in foreign language text comprehension: The role of interests and prior knowledge. The Modern Language Journal, 80 (1), 15-31. https://doi.org/10.1111/j.1540-4781.1996.tb01133.x

Burns, J. (2018). CRISTIANO AND LEO : The race to become the greatest football player of all time. London : Macmillan.

Carrell, P, L \& Wise, T, E (1998). The relationship between prior knowledge and topic interest in second language reading. SSLA, 20, 285-309. DOI: 10.2307/44485754

Deckert, G. (2004). Guidelines for the selection of topical content in ESL programs. TESL Journal Canada, Special Issue, 4, 73-88. https://doi.org/10.18806/tesl.v0i0.1041 
Esquivel, L. (1995). Like water for chocolate. United States : Perfect Learning.

Hedgcock, J, S \& Ferris, D, R. (2009). Teaching readers of English students, texts, and contexts. New York: Routledge.

Hidi, S \& Baird, W. (1988). Strategies for increasing text-based interest and students' recall of expository texts. Reading Research Quarterly, 23(4), 465-483. https://doi.org/10.2307/747644

Hidi, S \& Harackiewicz, J, M. (2000). Motivating the academically unmotivated: a critical issue for the $21^{\text {st }}$ century. Review of Educational Research, 70(2), 151-179 . https://doi.org/10.2307/1170660

Hidi, S. (2001). Interest, reading, and learning: Theoretical and practical considerations. Educational Psychology Review, 13(3), 191-209. https://doi.org/10.1023/A:1016667621114

Kintsch, W. (1980). Learning from text, level of comprehension, or: Why anyone would read a story anyway. Poetics, 9, 87-98. https://doi.org/10.1016/0304-422X(80)90013-3

Kintsch, W. (2013). Revisiting the construction-integration model of text comprehension and its implications for instruction. In Alvermann, D, E, Unrau, N, J \& Ruddell, R, B. (Eds). Theoretical models and processes of reading (6th ed.). Newark, DE: International Reading Association.

Maehara, Y. (2010). Learners' perceptions of gender-neutral language in an EFL textbook, Journal and Proceedings of the GALE, 3, 18-33. Retrieved on July $15^{\text {th }}$, 2020, from https://gale-sig.org/website/galejournalv3.pdf

Porreca, K, L. (1984). Sexism in current ESL textbooks. TESOL Quarterly, 18 (4), 705 724. https://doi.org/10.2307/3586584

Rezig, N. (2015). The learners' educational and cultural background effects' on their proficiency in learning English: The case of first year English students at Biskra university. Biskra, Algeria: Unpublished doctoral thesis. Retrieved on July 15 ${ }^{\text {th }}, 2020$ from http://thesis.univ-biskra.dz/1347/1/Ang_d3_2015.pdf

Rumelhart, D, E. (1980). Schemata: The building blocks of cognition. Spiro, R, J, Bruce, B, C, Brewer, W, F. (Eds). Theoretical issues in reading comprehension. Hillsdale NJ: Lawrence Erlbaum. Retrieved on September 6 ${ }^{\text {th }}, 2018$, from https://www.colorado.edu/physics/EducationIssues/zwickl/Resources/Rumelhart\%20Schemat a-The\%20building\%20blocks\%20of\%20cognition.PDF

Schraw, G., Bruning, R., \& Svoboda, C. (1995). Sources of situational interest. Journal of Reading Behavior, 27(1), 1-17. https://doi.org/10.1080/10862969509547866 